\title{
Issues in the Teaching and Learning of Children's Literature in Malaysia
}

\author{
Karen Kow Yip Cheng \\ English Language Department, Faculty of Languages and Linguistics, University \\ of Malaya, Kuala Lumpur, Malaysia \\ e-mail: kowyc@um.edu.my
}

\begin{abstract}
The Curriculum Development Centre of Malaysia implemented a Children's Contemporary Literature Programme to promote reading among pupils in year 4, 5 and 6 in schools. This paper explores some issues in the teaching and learning of children's literature in Malaysia. It also looks at the role of the teacher as well as the functions of children's literature. Further the English Language textbook and its role with reference to the teaching and learning of literature is analysed in this paper.
\end{abstract}

Key words: children, literature, reading, testing, teaching, textbook, learning, resources, language, meaning

The Children's Contemporary Literature Programme implemented by the Curriculum Development Centre of Malaysia aims to promote reading. In a research carried out by Kow (2006) on negation in children's literature, she found that there exists an innate tension between what an adult conceives to be children's literature and what the child conceives literature to be. The questions that beg answers are whether children are supposed to derive fun from reading a book or are they to learn from it?

This paper aims to study the following issues with special reference to Children's Contemporary Literature:

- What are some of the issues in the teaching and learning of literature?

- What is the function of children's literature?

- What is the role of the teacher?

- What is the role of the English Language textbook?

Lifelong reading is what the Children's Contemporary Literature programme hopes to promote. Kow (2002) points out that 'The objective of the programme is to create the willing, eager reader who not only 
masters the skills of literacy but also applies this mastery to achieve lifelong learning. Beyond that the skilled reader is the child who loves to read and the child who can't stop reading'. Hence this paper takes the reader on a journey to discover the answer to the question: 'Is Contemporary Literature a joy to pupils and teachers or is it an albatross?'

This paper serves as a sharing of experience of the issues in the teaching and learning of Literature with a focus in Malaysia. Perhaps other countries may share a similar experience. It is hoped therefore that this paper may pose as a learning experience in that what is good can be replicated and vice versa.

\section{THE FUNCTION OF CHILDREN'S LITERATURE}

Can one sentence truly define children's literature? What exactly is children's literature? The Curriculum Development Centre (2006) defines children's literature as: 'The material created for and widely read, viewed and heard by children, that has an imaginative element.”

Kow (2002) offers a definition that may be envisaged in Diagram 1:

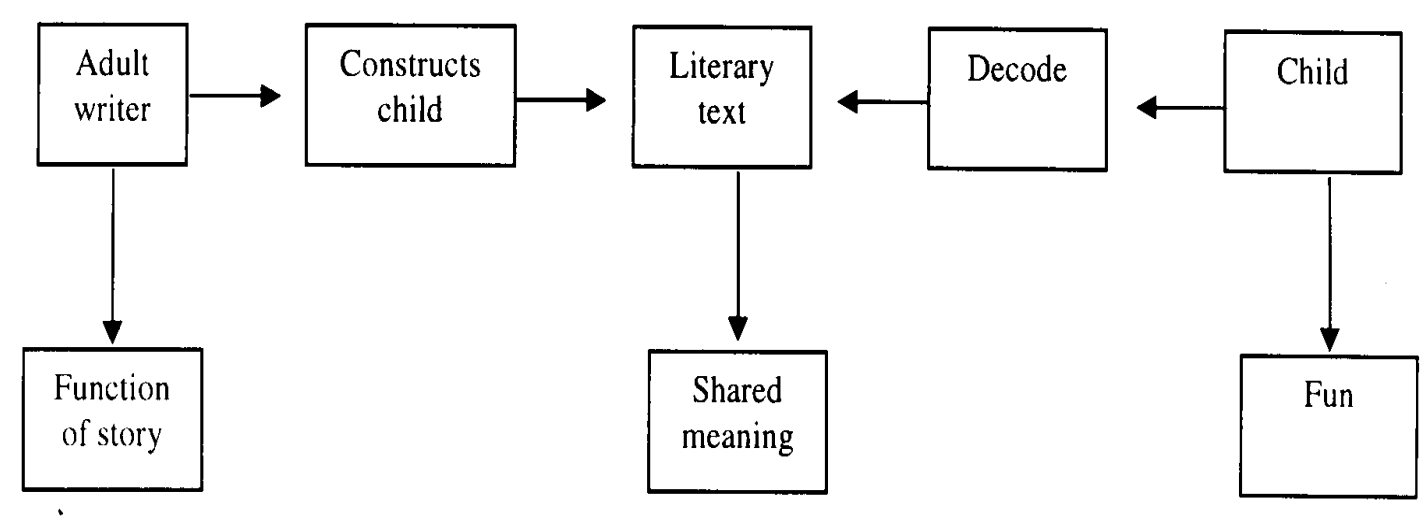

\section{Diagram 1. Children's Literature}

Children's literature is for children, be it read, viewed or heard. However, these stories are written by adults. Hence at the very onset, then, there exists a tension between what an adult conceives to be children's literature and what the child conceives literature to be. On the one hand, children want to derive fun from reading a book. On the other hand, adults view the functionality of books as one where there is a need for children's books to teach good moral values. 
Kow (2002, p. 48) noted that children's books are multifunctional. They help children to expand their imagination and to acquire literacy. Children's literature helps children to cope with problems be they social, cultural, racial or problems that crop up in dealing with life in the real world. It also helps to inculcate specific social attitudes that are deemed to be acceptable in their community.

These ties in with the learning objectives outlined by the Curriculum Development Centre for the literature component which are as follows:

- To instil and inculcate the reading habit among pupils.

- To enrich pupils' vocabulary and language content.

- To enhance pupils' thinking skills.

- To promote cultural understanding in the Malaysian context.

- To improve English language proficiency of pupils.

- To provide lively, enjoyable and high-interest readings.

Although last does not mean least, it is nevertheless reflective that the element of fun that tops the children's list is at the end of the teacher's list.

Nagy and Herman (1987) noted that even students who read relatively little, during the school year, will read about half a million words a year and be exposed in a year to 10,000 words that they do not know. In other words, the way to acquire a large vocabulary is through reading.

One therefore finds that while literature can be used as a tool to promote literacy and proficiency in the language, one should never lose sight of the fact that literature is meant to be enjoyed. Striking a balance between the two is not easy but it is not impossible. Children should be able to enjoy literature, to let their creative minds grow wings and fly to the realm of imagination! At the same time learning takes place not just in language skills, beyond that the child learns about people, culture, ethics and moral etcetera.

The Contemporary Literature program is one that assumes that every pupil will read at least two books in a school year. This intensive reading program is one where pupils are introduced to two different genres, that is, short stories and poems. For example the following short stories have been identified for standard six (age eleven) pupils:

1. The Perfect Present - Marcia Vaughan

(Ginn \& Company) Johore Central Store Sdn. Bhd.

2. Noble Tales Untold - Sheikh Hassan Seylan Abad

Abad Ceria Enterprise

3. Dan's Secret Weapon - Therese Rea

(Rigby Heinemann)- Alpha Sigma Sdn. Bhd. 
4. Clever Katya - Julia Donaldson

(Ginn \& Company) Johore Central Store Sdn. Bhd.

5. The Case of the Missing Maths Teacher - Suzanne Weyn

(McGraw Hill) - Refined Contour Sdn. Bhd.

6. Shorty - Christine Rule

SP Smart Resources Sdn. Bhd.

The curriculum Development Centre has very painstakingly listed the benefits of having children's literature in the school syllabus. Appreciation of literature brings about personal and emotional gains as enriching the children understanding of themselves and the world around them. Literature gives enjoyment while developing the imagination. It also helps children make sense of their own experience and evokes one's feelings on issues related to life.

The study of literature allows children to learn new ideas and knowledge. It adds to their understanding of concepts and cultural traditions and values and issues in life. Developing respect for self and others and encouraging one to become aware of one's audience are learning gains to be derived from the study of literature.

The study of literature aids in language gains as developing the children's awareness of how language works in communication and experiencing the form of narratives. It also allows them to experience new ways of using language that bridges the gap between written and spoken language. Literature also aids the learner in developing an understanding of the meaning of words.

\section{TWO LEVELS OF THE READING EXPERIENCE}

It is clear thus far that the literature programme in primary schools is one that has been planned with great care and deep thought has been given to pedagogy and the role of all parties involved, that is, both the teachers and pupils. However there is also the need to understand the actual reading experience. In looking at the functionality or the didactic value of children's literature, one should explore the experience that occurs between the reader and the text. This can be seen at two levels as depicted in Diagram 2: 
Level 1

Story = language used to encode story
Level 2

Story $=$ real psychological entity

Infused with magic and fantasy

\section{Diagram 2. Levels of the Reading Experience}

The actual experience that a child has with the story is one that cannot be easily analysed. Alderson and Short (1989) point out that:

It is known that the reader's understanding of a text will be conditioned by what he already knows, and by availability of that knowledge during the reading process ... it is likely that different readers will to some extent interpret different texts in varied ways ... as many interpretations as there are readers to interpret. (p. 72)

This is because the interface of text and reader is a very private and secret one. At the first level, the child is fully aware of the words and the language being used to create the story. On the second level, one sees an experience that may be equivalent to "pure magic". At this level, the conscious mind is put on hold and one flees the reality of this stressful world. The imagination is given free rein to construct a world that does not have to abide by the rules of the world, and the mind decodes the words and encodes the meaning in pictorial form, equivalent to a running movie. At this level the interaction is seen to be a personal one. The running shows that one child sees is different from that of another. The images are built using the existing individual world knowledge, values and perceptions. Hence it may be seen that the experience at level 1 can be similar, but the interaction at level 2 is a very private one.

\section{TEACHER'S ROLE IN TEACHING STORIES}

Having listed the benefits of learning children's literature, the question then arises as to the role that the teacher plays in the teaching and learning of literature in schools. The Curriculum Development Centre advocates that teachers read the story thoroughly with the pupils and highlight the story line, the characters in the story and the message or moral of the story. They go on to spell out exactly what needs to be done by the teacher. Among the suggestions offered are for the teacher to carry out the activities that have been suggested in the course. Further teachers are also encouraged to develop worksheets for pupils and to plan activities that pupils can put in their folio. Next teachers are to assess the folio that pupils have completed. Finally, teachers are also encouraged to create an enjoyable learning environment by devising activities suited to their pupils. 
On the opposite side of the coin is the role played by the pupils. CDC suggests that the pupils read the book/poem and then talk about the book/poem to his/her friend. They are encouraged to complete all exercises given by their teacher and to get involved in classroom activities. Pupils are to write down all the new word they have learnt in a vocabulary book. Further they are advised to keep a folio that has the following components:

Table of Contents

Pupil's Work

Dates

Drafts and Final pieces

Reflections

Most importantly the pupils are encouraged to carry out self assessment, that is, to reflect on their own learning.

\section{EXPLOITING THE RESOURCES}

The Curriculum Development Board has done a good job in ensuring that there are resources for the Contemporary Literature Component. In this section, an example of the resources provided for the 'The Case of the Missing Maths Teacher' is highlighted.

Materials provided for the component include power point slides and a guide. The power point slides walk the teacher through the plot, setting, characters, lessons learnt and the emotions evoked by the story. It is the role of the teacher to exploit these resources. There is the need to balance the need for learning and the need for the learning to be fun. Hence in exposing the pupils to plot, character etcetera the teacher can try to inject fun by allowing pupils to role play or even to dramatize the story.

Activities which are suggested include pre-reading, during reading and post-reading exercises. For example, pre-reading activities include exercises on wh-questions, gap filling, sequencing and rearranging of pictures to form a story. Higher level skills are also tapped, for example writing sentences from given words and writing a short paragraph with a non-linear input. Again exploiting these activities is important. The pupil has had enough activities to do during English language classes and they may not be excited about more work. The teacher has to try to package these comprehension questions and paragraph writing into fun activities. For example, the paragraph writing can take the form of group work where pupils are writing a script which they can then act out. Exercises on wh- 
questions can be used as a class competition and where the names of the winning group members can be displayed on the class bulletin board etcetera.

Pupils should be exposed to the fun activities as role-playing and dramatization. The need to express oneself and one's emotions is addressed in activities where pupils are encouraged to talk about which characters they like or dislike.

Testing is never far away from the mind of a teacher. Hence one sees the influence of the UPSR examination in some activities, for example, in the Rebus writing activity, an activity uses pictures to prompt the testing of vocabulary. The UPSR is an examination which is carried out nation wide for all year six pupils age twelve. The Rebus writing activity is a format that is used in the UPSR examination. This is an exercise where pictures are provided and the pupil is expected to come up with the word. In other words, it is a test of vocabulary via a non-linear or pictorial input. An example is provided below:

The

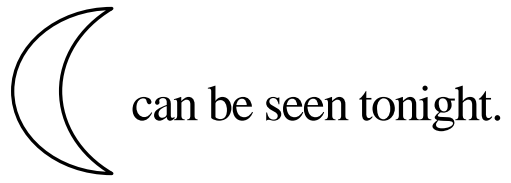

The moon can be seen tonight.

Being tested is never fun but teachers may try to exploit the UPSR examination in a positive way. Hence testing formats that are in the UPSR paper may be used to exploit literary materials. For example, the literature texts can be used to improve sentence writing and short paragraph writing skills.

\section{THE ROLE OF THE ENGLISH LANGUAGE TEXTBOOK}

In the writing guidelines for the English Language textbook, there is a specification that books for the Contemporary Literature program must be utilized in the textbook. Under the requirement of appropriate additional materials, the guidelines include:

Additional appropriate materials may be included, other than the basic learning materials, to encourage further reading for knowledge. For example, the books for contemporary literature introduced by the Curriculum Development Centre could be used for this purpose. An excerpt of the text should be included before any activities and/or exercises are presented, for easy reference. 
While the cause is worthy, the translation of the requirement into paper may be questionable. The way to go may be to provide an excerpt from the literary text as a reading text. The next activity then to assess reading comprehension will be to have comprehension questions ranging from True/False questions to wh-questions. While there is nothing wrong with exploiting a literary text via comprehension questions, it is a case of under exploiting the literary richness of the text. It has been pointed out that a reader actually engages with a text and hence points like feelings evoked by the reading and issues that are raised via the text needs to be exploited.

Hence the comprehension questions may be practical and necessary; nevertheless the teacher can move beyond and exploit the literary text to tap on the pupils' feelings about themes, plots and characters. Further pupils should be encouraged to explore issues that include moral and ethics. For example, a well-known animal tale in the Malay language is Sang Kancil. This is about a mouse deer, an intelligent trickster who plays dead when he is caught in a trap. Although on the surface Sang Kancil is no more than an animal story, behind it is its use as a socialising tool. Hence stories like this one can be used to explicate correct moral, religious and cultural values on the one hand, and on the other they validate beliefs that are strongly held by a particular community.

The beauty of the language, the play and pun of words and the joy of rising beyond the real world to the world of imagination is what literature is about. As a phoenix that rises from the fire anew, so the child who engages with a literary text has his creative fires flamed by the winds of imagination.

\section{WHAT THE TEACHERS HAVE TO SAY}

While a trained teacher has the ability to exploit a literature text to teach a variety of skills including vocabulary and the past tense, an untrained teacher will probably need a bit more help. Teachers who are not trained to teach English may in their over zealousness end up 'murdering' a literature text by making the pupils read it again and again. Perhaps it is felt that by some magic formula reading the text repeatedly brings about comprehension and literacy. The Curriculum Development Centre sees the literature component as one that not only addresses language but also cultural learning as seen in the learning gains listed earlier. These include providing lively, enjoyable and high-interest readings, allowing children to 
understand cultural traditions and values and issues in life and enriching their understanding of themselves and the world around them.

Teachers who have a class of weak students definitely have their work cut out for them. To help the pupils and the school, teachers are advised to focus on the UPSR examination. Teachers spend all their time coaching weak students on techniques of passing the UPSR English paper. By so doing the pupils pass the English language paper and the school can report an impressive percentage of A's and passes for the UPSR examination. Hence the focus is on the examination and the literature component has to take a back seat.

Some of the teachers feel that as long as the literature component is not tested, schools will not take the component seriously. These teachers who talked to the researcher went on to suggest how this can be done. The present UPSR paper is marked upon $80 \%$. This $80 \%$ total mark is derived from paper 1 and paper 2 with the following allocation of marks:

Paper $1-40 \%$

Paper $2-40 \%$

The teachers suggest that $20 \%$ be allocated to the contemporary literature component hence bringing the paper to a total mark of 100\%:

Paper $1-40 \%$

Paper $2-40 \%$

Contemporary Literature - 20\%

Kow (2003) notes that teaching a literary text as reading comprehension merely teaches understanding of the story. Literature, on the other hand, goes on to instil the love of reading. Hence the role of the teacher is to instil this love for life-long reading. It goes without saying then that one can only pass on the appreciation of literature when one can appreciate literature oneself. One is therefore left with the very unpleasant question of whether 'testing' literature is the way to go. Can the love of literature and the love of reading be instilled via testing? On the other hand, will literature be taken seriously if it is not a component that is tested? There is no quickfix answer to the questions posed here but one thing is obvious. The literature component has to remain and it has to be 'marketed' not only to teachers, but also to administrators and parents. It is a fact that if there is no literature component then the journey to life-long reading and the love of reading will never be inculcated in pupils! 


\section{AVAILABILITY OF RESOURCES}

It is interesting to note that several teachers have on their own drawn the conclusion that funds for the implementation of the Contemporary Literature component must be running out. They note that when the project began with the standard four pupils, schools were provided with four sets of thirty-five books. In the following year, that is for the standard five pupils, the schools were provided with four sets of fifteen books. This year the standard six pupils were provided only four sets of fourteen books per school. Given the fact that each school has an enrolment of at least a hundred over pupils, this spells 'big problems' for the teachers. Even given the fact that not all one hundred plus pupils use the book at the same time, the fact is one class has more than fourteen pupils! Although schools can purchase the books from the publishers, teachers report that they have contacted the publishers and have been told that there are no available copies. To think of making copies of the books will be illegal but it has been done. One teacher reports that this defeats the very purpose of literature which is to enjoy reading and at this level the experience involves not just engaging with linear text but also with the non-linear. The child is to enjoy the literary experience of matching text to beautifully illustrated pictures or drawings! With a Xeroxed copy this joy of engaging with illustrations is lost.

If the hurdles mentioned above do not appear daunting enough, how about the fact that only one period is allocated per week for the Contemporary Literature component. The length of the literature period, all of thirty minutes is what is on the time-table.

Having faced the fact that resources are limited as they will be in any realistic situation, it is left to the teacher to break the boundaries of creativity. If there are not enough books available can one then move beyond just reading the story to getting the pupils to create their own script and acting out that script. What about incorporating literary texts into English language lessons as suggested earlier and doing exercises linked to examination-type questions that are literary in content!

\section{THE ROLE OF THE PARENTS}

Having explored the role of the Curriculum Development Centre, the Textbook Division, the teacher and the pupil what then is the role of the parents? Perhaps the most important role is that to nurture the love of 
reading. Children's literature should fulfil not just the didactic needs but more so the needs of children. "The objective is to create the willing, eager reader who not only masters the skills of literacy but also applies this mastery to achieve life-long learning. Beyond that the skilled reader is the child who loves to read and the child who can't stop reading” (Kow, 2002, p. 44).

In other words, children's literature should excite children and not just be didactic. Once a child enjoys reading at both levels 1 and 2, it is assumed that he/she hones the skill of literacy (see Diagram 3). One does not need to teach decoding and language skills overtly. Rather it is assumed that through the reading process, the child develops literacy and linguistic skills. It is through interaction with the text on both levels - as text created in language and as text that functions as a launching pad for exploring imaginative realms - that the child develops reading and learning strategies.

The role of the parent, caretaker and educator is outlined by the author (2002, p. 53): The facilitator should take time to reflect on the story. At this point the facilitator can help the child to put the words in a story within a context and to exploit the contextual clues provided by the pictures. Questions at this level may include ones pertaining to values be they cultural, religious or gender based. It is at this stage that textual meaning is raised to the level of world meaning. It is also at this level that the child can be equipped with critical skills that will make this child an empowered learner for life. Reflection will raise the child from an acquirer of knowledge to that of user of knowledge.

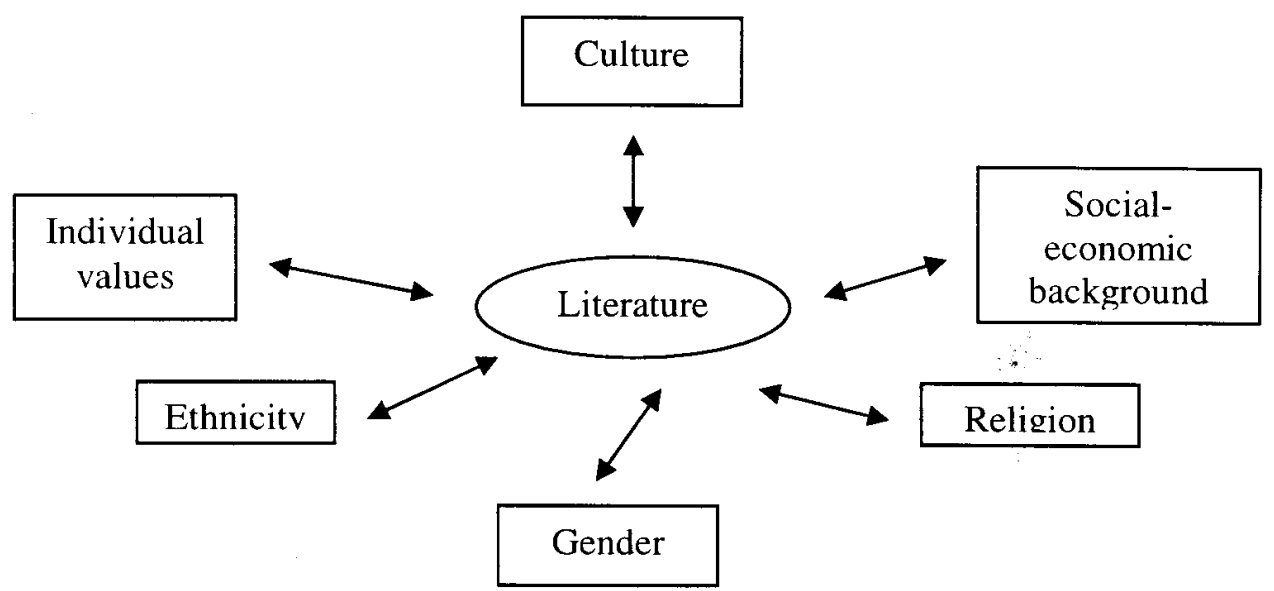

\section{Diagram 3. Representation of How Literature Is Socially and Cul- turally Situated}


In recognition of the fact that many parents today are stretched for time, a practical solution would be for parents to be role models themselves. In other words, read if you want your child to read. Ideally the parent and child should spend some time reading together and as a treat, a weekend can be spent watching movies that have a book tie-in. This can be followed by an outing for a snack or a meal where the child and parent can discuss issues, themes, plots, characters, moral values etcetera. Frivolous as it may seem to watch a movie, the learning that can take place would include those on a literary, social, cultural and economic level. The child will be exposed to real issues that one is faced with on a day to day basis. Further skills learnt will include those of listening, speaking, thinking, moral and ethics among others.

\section{CONCLUSION}

One finds then that are many issues in the teaching and learning of children's literature. Perhaps one may feel that the heydays of literature are over:

Without doubt the heydays for literature in English as an academic subject within the Malaysian educations system was during the British rule of Malaya and the period of post-independence when English remained the medium of instruction. The change in the medium of instruction to Malay also meant a change in the overall objective of education in the country to one directed at nation building. Within this new paradigm there was little place for the teaching of literature in English. (Subramaniam, 2002, p. 37)

On the other hand, the work done by the Curriculum Development Centre and the Textbook Division is exemplary. The Curriculum Development Centre has not only prepared material for the component, they have also carried out training sessions for the teachers. The Textbook Division has ensured that activities based on the Contemporary Literature Component are included in the English Language textbook. It can be seen therefore that the policy and policy makers uphold and believe in the need for there to be a literature component. This is the crux of the matter. Without the belief and support of the Ministry of Education in the importance of literature as a component in the syllabus, the death of literature is a sure thing. 
There is perhaps the need to move beyond literature as small 'l' into Literature with a big ' $L$ '. Literature as small 'l' can be taught via a language based approach that only ends at surface meaning. It focuses on the use of connectors, persuasive language, new words and deducing their meanings from context. Literature as big ' $\mathrm{L}$ ', however, goes beyond that because language is used to reach out to the imagination and emotion of readers. In other words, "the objective is to create the willing, eager reader who not only masters the skills of literacy but also applies this mastery to achieve life-long learning. Beyond that the skilled reader is the child who loves to read and the child who can't stop reading” (Kow, 2002, p. 44).

Parents, teachers and caregivers need to remember that they should not overplay the importance of the learning opportunity derived from meaning, be it that of moral or comprehension skills. There is the need to nurture the love of reading: "The sheer enjoyment of losing oneself in a world that is real yet not bound by realism but freed through imagination. The language of story telling is the language of imagination where language is used by the child to create his own environment” (Kow, 2002, p. 48).

A worthy cause comes with a price. The suggestion that even weak pupils can cope with and go on to enjoy literature may be difficult to accept. Nevertheless the reality of the situation is that resources will always be limited, pupils will come with differing levels of ability and national examinations will always exist. However if one exploits what one has, that is, if the teacher tries to inject fun into literature and make literature relevant to pupils; and parents try to set aside time to perhaps watch a movie that has a book tie-in, then all parties will benefit from the literature component. As Huck (1976) sums it up accordingly: "good writing ... will help the reader to experience the delight of beauty, wonder, and humor ... he will be challenged to dream dreams, to ponder, and to ask questions to himself' ( $p$. 4). If one believes in the magic of a story then one sees the world encapsulated in a grain of sand. The experience of reading at a higher level is as seeing the world in a grain of sand (Kow, 1993). In other words, if the love of literature is inculcated in pupils then one can stand to reap life-long rewards not only in the area of learning a language but also in the area of moral, ethics, and culture etcetera. 


\section{REFERENCES}

Alderson, J. C., \& Short, M. (1998). Reading literature. In M. Short(Ed.), Reading, analyzing and teaching literature quoted in P. Hunt (Ed.), Understanding Children's Literature (pp. 1-14) London: Routledge.

Kow, Y. C. (1993, June 13). Literature’s the language of life. Sunday Star.

Kow, Y. C. (2002). Literacy and pre-school children: story-telling strategies. In M. K. David, \& F. Hashim (Eds.), Developing reading skills (pp. 43-54). Malaysia: Sasbadi.

Kow, Y. C. (2003). Language and culture: The story of children's literature. Australian Language Matters, 2(2), 4-7.

Kow, Y. C. (2006). Negation in children’s literature. GRAAT, 35, 297-309.

Huck, C. S. (1976). Children's literature in the elementary school (3 ${ }^{\text {rd }}$ ed.). New York: Holt, Rinehart, \& Winston.

Landsberg, M. (1987). Reading for the love of it: Best books for young readers. New York: Prenctice-Hall.

Nagy, W. E., \& Herman, P. A. (1987). Breadth and depth of vocabulary knowledge: Implications for acquisition and instruction. In M. G. Mckeown, \& M. E. Curtis (Eds.), The Nature of vocabulary acquisition. Hillsdale, NJ: Erlbaum.

Subramaniam, G. (2002). Reading through literature and literature through reading: The incorporation of a literature component in the Malaysian ESL syllabus. In M. K. David, \& F. Hashim (Eds.), Developing reading skills (pp. 55-74). Malaysia: Sasbadi.

Kursus Pelaksanaan Program Bacaan Sastera Kontemporari Kanak-kanak Bahasa Inggeris Tahun 6. [Children's Contemporary Literature in English Programme for Year 6]. (2006). Pusat Perkembangan Kurikulum [Curriculum Development Board]: Kementerian Pelajaran Malaysia [Ministry of Education Malaysia]. 